\title{
Visions by WIMIN: BIPOC Representation Matters
}

\author{
Jenny N. Ijoma ${ }^{1,2}$, Mahnue Sahn ${ }^{3}$, Kyeara N. Mack ${ }^{4,5}$, Eman Akam ${ }^{6}$, Kimberly J. Edwards ${ }^{7}$, \\ Xiaowei Wang ${ }^{8}$, Anmol Surpur ${ }^{9}$, and Kelly E. Henry ${ }^{4} \odot$ \\ ${ }^{1}$ Rutgers, Robert Wood Johnson Medical School, New Brunswick, NJ, USA \\ ${ }^{2}$ Princeton University, Princeton, NJ, USA \\ ${ }^{3}$ Central Connecticut State University, New Britain, CT, USA \\ ${ }^{4}$ Memorial Sloan Kettering Cancer Center, New York, NY, USA \\ ${ }^{5}$ Weill Cornell Medical College, New York, NY, USA \\ ${ }^{6}$ Harvard Medical School, Boston, MA, USA \\ ${ }^{7}$ University of Pennsylvania, Philadelphia, PA, USA \\ ${ }^{8}$ Baker Heart and Diabetes Institute, Melbourne, Australia \\ ${ }^{9}$ Carnegie Mellon University, Pittsburgh, PA, USA 2021
}

\begin{abstract}
Racial, ethnic, and gender representation in an academic setting means that teachers, professors, and other leaders reflect the demographics of the student body in the educational and professional spaces that they serve. This form of representation, which is often intersectional, strengthens communities and improves student outcomes, from as early as primary and secondary education, through to college education and beyond. Representation matters because it can shape the reputation and self-image of women and Black, Indigenous, and People of Color (BIPOC) within environments dominated by over-represented majorities (ORMs). From the perspective of BIPOC women trainees, the lack of BIPOC faculty who are visible minorities, particularly at the most senior level positions, often conjures questions of whether academia is a realistic career path for aspiring minority students. This article focuses on the key component of representation in the United States (U.S.), highlighting our vision for a solution for the so-called "leaky pipeline" for BIPOC in science, technology, engineering, and mathematic with action items to end it.
\end{abstract}

Key words Representation · BIPOC · STEM - URM · ORM · Black

\section{Introduction}

"You can only aspire for what you can see yourself in," was a common refrain of the few Black academics in the United States (U.S.) who, against several odds, found themselves in a position of authority. The percentage of Black academics dwindles as one moves further up the academic hierarchy of science, technology, engineering, and mathematics (STEM) education and respective careers. This could be attributed to a "leaky pipeline," a simple analogy that describes

Correspondence to: Kelly E. Henry; e-mail: Kelly.henry89@ gmail.com this percentage decline for Black people in STEM [1-3]. Data shows that in the U.S., representation of underrepresented minorities (URM) decreases at each degree level for STEM when compared to White and Asian students [4]. In 1988, women graduate students in science-related programs composed of $32 \%$ of their class, and this figure rose only by $4 \%$ when reexamined in 1993 [5]. However, women were less likely to pursue science-related employment, resulting in only $24 \%$ of science faculty in that same year [5]. In 2010, URM accounted for only $14.7 \%$ of STEM bachelor's degree recipients and a dismal $8.3 \%$ of STEM doctorate degree recipients. When looking at women alone 
receiving doctoral degrees in STEM, there has only been an increase of $12.1 \%$ from 1999 to 2019 [6]. The portion of Black, Indigenous, and People of Color (BIPOC) women in STEM receiving degrees around this time has risen at a significantly lower rate. Only $31 \%$ Black women and Latina women and 4.7\% Asian women received STEM bachelor's degrees from about 2008 to 2018 [6]. Natives were $0.2 \%$ of STEM bachelor's degrees, with Native women being underrepresented in engineering and computer science specifically [7]. The data is discouraging, especially when the amount of URM STEM data drastically narrows as educational level increases and is depicted inconsistently [6]. We optimistically examine history in hope that these numbers would trend in a more positive manner, but we are clearly missing a driving force to push BIPOC women into these careers. Psychological and social disparities often perpetuate the leaky "pipeline" that leads to decreased representation of minorities in higher education [4]. URMs often come from families in lower socioeconomic groups where education may not be highly emphasized due to a more immediate need to work and contribute financially to the household [8]. Students from these socioeconomic groups often must work full or part-time while in school, limiting their engagement in their studies [9]. These additional stressors and responsibilities can impact academic achievement by limiting time to study and time to participate in STEM research programs. Students who are interested in STEM then additionally deal with a stigmatizing academic culture that does not see them as capable of success in these predominantly White fields [10]. All these issues can deter URM students from pursuing higher degrees and/or faculty positions in STEM. The lack of URM STEM faculty then continues to create these unideal environments for URM, further propelling the cycle.

Ironically, despite that fact that existing data shows Black STEM underrepresentation, there is a dearth of addressing the social determinants hoisted from unresolved structural racism that lead to this underrepresentation [8]. Underrepresentation does not start and stop with a think-piece on the pipeline analogy where we have chosen to identify a problem and accept mediocre changes [8]. A triadic theory centered on critical race theory, gender theory, and sense of community belonging suggests that many factors play a role in the underrepresentation in the STEM field among urban youth [11]. The complexity of factors that lead to underrepresentation of Black students in STEM further supports the necessity of a framework of social determinants of education. This complexity further highlights the reason why seeking a panacea solution to Black STEM underrepresentation, such as adding more young Black students, is ineffective.

Of the over-represented majorities (ORM) in the scientific community, we have failed to consider if opportunities for involvement in and aspiration to STEM academic careers for Black and Brown communities truly exist. There are no existing models to emulate for Brown or Black youth who might have considered STEM. Families of low socioeconomic status are unable to access placement in the "pipeline" in the first place. Obstacles, such as registration fees, limited literacy skills, a scarcity of resources to acquire the necessary scientific knowledge, and access to the application processes, all severely limit access to the pipeline from the start [12]. Additionally, little effort has been placed to determine the existing problems preventing Black students in low socioeconomic school districts from attending school. Despite the lack of effort to uncover the root of the problem, the outcome (defined as a limited number of BIPOC participants) is often blamed on "lack of interest." This is a cycle of its own because this racial bias takes the form of discrimination and persists across each generation of leadership.

The usual solution, often stated for the leaky pipeline problem, is to increase the number of students from the very beginning, but this alone is not sufficient, particularly in the case of Black STEM students [13]. Being Black in countries like the U.S. and receiving the education and credentials necessary to be eligible for academic positions like professor or investigator means navigating societal determinants that influence the accessibility of STEM education for Black people [14]. A lack of social and/or economic capital alone is more than enough to prevent students at any age from attending school; supplementary after school STEM programs can therefore be out of question entirely. For URMs who make it as far as graduate school, dedicated mentoring programs and the support of an understanding mentor is vital for their success. For BIPOC women like us, matching a mentor with a mentee should not only be based on shared backgrounds and scientific interests. Someone who serves as a mentor for BIPOC students and us should be well-equipped to handle this terrain, be present, and give guidance and support, while advocating and assisting in charting the mentee's career path.

\section{Perspective}

\section{Kyeara N. Mack: Lack of Representation in Graduate School}

In 2018, I started as a graduate student at Weill Cornell in the Pharmacology PhD program. I was one of two Black female students in my incoming year. Looking around at the upper years in my program I could count on one hand how many other current Black students there were (all Black women). The representation of women in my program is phenomenal, and there is decent representation when it comes to other POC. However, the representation of Black people, and especially Black men, is very poor.

One may think that the solution to this problem of lack of representation would be to recruit more Black students into the program. However, this alone is not enough, and more focus should be placed on providing the tools and 
mentorship that we actually need to encourage retainment. Students of all races enroll in STEM majors at similar rates; however, Hispanic and Black students switch majors at much higher rates than White students $(37 \%$ \& $40 \%$ vs. $29 \%$, respectively) [15]. In addition, Hispanic and Black students who enroll in STEM majors drop out without a degree at higher rates than White students $(20 \& 26 \%$ vs. $13 \%$, respectively) [15]. These significant gaps are not seen in other majors such as business or the social sciences. This shows that although BIPOC student recruitment is important, more efforts must be made in student retention in STEM education.

Black students need to excel and complete the PhD program. It is not enough to just enroll Black or BIPOC students into higher education programs. Every student is different with various backgrounds/experiences and thus every student should be provided the appropriate mentorship for their individual needs. Additionally, institutions and departments need to actively provide adequate resources to address the needs for us minority students and ensure our success. An example of such a resource is the Safe Space \& Open Dialogue (SOS) group recently created by the Weill Cornell Social Justice \& Anti-racism (SJAR) Task Force. SOS provides a safe space to discuss social justice issues and share experiences. More importantly, SOS provides students with a library of resources including a book club that facilitates open dialogue on racism.

The SOS group discussions have provided me with a virtual safe space to educate myself on combating racism in academia. I have participated in multiple discussions on the following topics: Anti-Asian Hate, Remembering George Floyd, Confronting Racism in Academia, India COVID Crisis, and the Humanitarian Crisis in Palestine. These open dialogues have given me the opportunity to express my concerns on racism as well as educate myself on issues pertinent to other races and cultures. Participating in SOS has provided me with a supportive community of scientists and has helped me to build confidence as I continue in my $\mathrm{PhD}$ program.

As a Black woman who has been inspired to be a scientist since high school, I have not had many women, let alone Black women, as mentors. The mentors that I have had in the past (White men) have been instrumental to ensuring I was on the right path to graduation (e.g., completing and passing my courses). However, I lacked a social connection with them. I often noticed faculty favoritism for White women students, and I felt overlooked a lot of the time. These experiences contributed to my diminished sense of belonging and caused me to question my intelligence. In graduate school, I have been grateful to have a more diverse group of mentors who have significantly helped me along the way. However, there is still minimal representation of women and BIPOC faculty in higher education. Young women students often must deal with patronizing and demeaning male mentors, which can have a detrimental effect on their mental health and path forward. The lack of BIPOC faculty representation in higher levels of science education can impact BIPOC application rates and retention. It is vital to create more diverse faculty boards with individuals who value the importance of mentorship and are not just a part of the Office of Diversity and Inclusion. Studies have shown that having gender and identity matched mentors is important to student success [16, 17].

Mentorship is known to be critical in the development of students at all levels for their personal and career development. This becomes even more important for URM students who often face unique challenges that their non-minority counterparts may not experience. Due to the lack of representation of minorities in scientific higher education [18], BIPOC students often face stereotypes that undermine our intelligence and our ability to succeed in such environments. These stereotypes readily create environments that perpetuate our imposter syndrome and diminish our sense of belonging. Therefore, mentors who actively educate and sensitize themselves to the issues that we face are vital to our success.

Successful mentor to mentee interaction is often defined by how "productive" a student has been, which is usually measured by publications, grants, and other awards. Although important, these benchmarks do not accurately reflect faculty mentorship success. A highly productive student can still be mentally neglected by their mentor who does not attend to their social needs. Mentors should task themselves with "aiding in students career decisions, providing students with access to diverse, professional networks and visibility, keeping students informed and knowledgeable about what is needed to finish their degrees, and land a position of the students' choice" [19]. Faculty should be aware that in addition to the abovementioned tasks, minority students may also need to be mentored in ways that uplift and reinforce their competence and goals.

\section{Discussion}

It is an unfortunate reality that many young Black people often fail to recall someone in their personal life that has a STEM career, and we must address this frankly in order to fix this [20]. Several complex factors contribute to this lack of representation. In the first place, a significant number of Black students will never receive an equitable opportunity to pursue and receive an undergraduate or graduate level STEM education. Once a Black person overcomes such hurdles and begins pursuing their academic degree or started their career in STEM, they are vigorously met with an onslaught of racial abuse that can manifest in feeling intellectually inferior by colleagues, being antagonized, or even physically attacked [20]. Young Black students have and increasingly reported their feelings of unwantedness in their academic spaces and the toll of energy they must exert to feel safe in these spaces [21-23]. Safety, and lack thereof, has been a significant player that we see as a lack of Black STEM representation. Black 
people endure abuse and experience racial trauma, and usually have to rely on their own communities to support them through these difficult chapters in their life as they struggle to make meaningful contributions in STEM [24]. These negative experiences can be mitigated immensely with proper support in place to remind and reaffirm to Black students their right to occupy space and to succeed. This support would also become significantly strengthened by mentors (even if not specifically trained to do so) recognizing its pitfalls and imperfections and making an ongoing effort to commit to learning from their mistakes and committing to improving the situation for their mentees.

Academic institutions retain their Black students at a significantly lower rate than their White students, but question why there are low numbers of Black students enrolled [25]. Academic institutions then double down on their advertising and financial investment to encourage more Black students to enroll in their courses or work in their buildings. But once they are accepted, the institutions do not offer any strategies to address the students' specific needs or help them to achieve success or feel wanted. In many cases, these institutions fail to recognize that there is even a problem to solve [25]. This phenomenon and the adverse effects of feeling unwanted and unwelcome in the academic community have become incredibly evident in the past year with the mental health of young Black students significantly improving because they were not required to physically attend school due to the COVID-19 pandemic [26, 27]. For Black students, physically occupying the same institutions that many non-Black students attended means fielding racist comments from their classmates and intimidation from over-policing in their hallways [23, 28].

Black students, who are already burdened with the mental and physical fatigue associated with summoning the endurance to fight through oppressive academic systems, are often not given a compass to use in their academic journeys. Black trainees are rarely provided the opportunity to receive the mentorship they need that offers them perspective on what they should do to be successful as Black students in STEM $[29,30]$. This is perpetuated in some areas of low socioeconomic status where institutions do not have adequate funding to support extracurricular programming that would connect Black students interested in STEM to professionals in the fields they are dreaming about pursuing [31]. Even in institutions where said programs are created, adequate mentorship is not often provided to Black students [32]. If a trainee is passionate about pursuing a specific career and she/he/they often have the option of either having a mentor that is White (or does not match their ethnic/racial/cultural identity) or no mentor at all, receiving advice from someone who cannot relate to the barriers you face daily is comparable to the idea of losing access to privilege and power. Representation is power and privilege, and it takes a resilient individual to have to continue fighting and advocating for the support they need and deserve when the rest of the world thinks they have solved the problem already.
A mentor is responsible for providing resources to their mentees, like how teachers in academic settings are responsible for providing the resources that their students need because their students are in positions of vulnerability. Accountability inherently lies with the mentor, not the mentee. The mentee, as autonomous as they are, places their trust in their mentor. A mentor who may advise you to network and without understanding the anxiety you have with cold calling or a mentor that may link you to another individual that has their own implicit biases could prevent this mentor from being helpful [33].

\section{\#ShutDownSTEM}

On June 10, 2020, researchers across the country joined forces in a strike against academic institutions in the wake of the murders of Black people in the country [34-37]. These researchers came from dozens of institutions and participated in a national protest systemic racism rooted in their academic research. Anti-Blackness and prejudice are embedded in many publications of academic research [38-40]. The strike was a day of action; reading and listening materials were solely dedicated to racism against Black people. Several prominent hashtags such as \#ShutDownSTEM, \#ShutDownAcademia, and \#StrikeforBlackLives circulated on social media. \#ShutDownSTEM yielded several outcomes in favor of this movement. For example, several organizations such as Nature [41], the American Physical Society [34], and the American Association for the Advancement of Science [34] were in full support of the demonstration. Likewise, the School of Science at Massachusetts Institute of Technology participated by forming programs and discussions across different institution departments in an effort to push for advocacy [42].

\#ShutDownSTEM was a wake-up call and demonstrated the layers of anti-Blackness in the field of STEM that persisted from high school students to senior investigators in major academic institutions. To understand the sentiments of the academics participating in the protest is to recognize the big picture: systemic racism has and continues to infiltrate all levels of education. Even those who have gained tenure in their respected careers must endure the consequences of a system that has actively deterred their success. So far, efforts to advocate for antiracism on an institutional level have not been well received. A group of physicists known as Particles for Justice, stated the following: "We are not asking people to sit through another training about implicit bias..." [37]. To assume that one may solve the issues deeply rooted in systemic racism with programs like implicit bias training is ludicrous. The daily hardships experienced by Black and Brown academics, and those looking to enter the field, cannot be understood through one session of training, one book, one lecture or one video. 


\section{Conclusion}

The tools we have tried to use to educate our institutions and communities on antiracism need major change. Institutions need to live and breathe antiracism. Our terminology needs to be more forthcoming and explicit. We do not need to work on addressing bias, but on addressing and eradicating the racism that exists in our institutions and prevents us from serving our communities through the people in power that affect them. Black students need to feel safe speaking up against racism and their voices need to not only be uplifted but said in tandem with other supportive antiracist non-Black students [43]. This is especially important for Black students and professionals who need to relive their trauma to educate others without their consent. There should be more platforms created for reporting racism, as well as increased accessibility. These platforms can take the form of drop boxes, forums, check-ins, or more. More importantly, they should offer participants anonymity and protection from retaliation. Black students and professionals need to be offered the opportunity of sitting at the head of an institutional organization where they can show their community that they have their best interests at heart. Individuals in supervisory roles need redesigned accountability systems with clear descriptions of conduct outlining what is acceptable and unacceptable. The implicit bias training programs that institutions provide needs to be overhauled to introduce daily accountability and activism, not an annual online module that needs to be completed by only most of the department. Each supervisory role, be it a mentor, manager, or principal investigator, needs to be comfortable feeling uncomfortable with the work that it takes to be antiracist. As mentioned in this article, "You can only aspire for what you can see yourself in," therefore, representation matters when you are looking at diversity and inclusion. Representation is needed to encourage retention of BIPOC in science and research, as well as to get people interested and involved at a young age. We all need to work with being actively antiracist to avoid being complicit to the oppressive systems hurting our communities and disvaluing the worth of those within them. Most importantly, do not rely on Black people to relive their trauma to educate you.

\section{Declarations}

Conflict of Interest The authors declare they have no conflict of interest.

\section{References}

1. NSF: NCSES. Foundation, Women, Minorities, and Persons with Disabilities in Science and Engineering (2019) [Link]. Accessed July 2, 2021

2. K Mulhere, Gender stereotypes in STEM. Inside Higher Ed (2014) [Link]. Accessed July 2, 2021

3. E.T. Service, The STEM pipeline (2015) [Link]
4. Estrada M, Burnett M, Campbell AG, Campbell PB, Denetclaw WF, Gutiérrez CG et al (2016) Improving underrepresented minority student persistence in STEM. CBE Life Sci Educ 15(3):5

5. Burrelli J, Arena C, Fort D, Shettle C (1996) Women, minorities, and persons with disabilities in science and engineering. DIANE Publishing, Social Science

6. National Center for Science and Engineering Statistics (2021) Women, minorities, and persons with disabilities in science and engineering: 2021. Special Report NSF 21-321. Alexandria, VA: National Science Foundation. Available at https://ncses.nsf.gov/ wmpd. Accessed 12 Sept 2021

7. Native American participation among bachelors in physical sciences and engineering: results from 2003-13 data of the National Center for Education Statistics (2017) Focus On Merner, Laura, Tyler, John AIP Statistical Research Center. Available at http://www.aip.org/statistics. Accessed 12 Sept 2021

8. Stevenson, MML. Agrawal RK, Gloster C. Understanding the reasons for low representation of ethnic minority students in STEM fields. ASEE $123^{\text {rd }}$ Annual Conference \& Exposition. June 26-29, 2016, Paper ID \# 14419

9. Rozek CS, Ramirez G, Fine RD, Beilock SL (2019) Reducing socioeconomic disparities in the STEM pipeline through student emotion regulation. Proc Natl Acad Sci 116(5):1553-1558

10. Malcom ES, Feder M (2016) Committee on barriers and opportunities in completing 2-year and 4-year STEM degrees. Systemic change to support students' diverse pathways. The National Academies of Science, Engineering, and Medicine. The National Academies Press

11. Williams ML (2020) How out of school time programs at field-based science institutions impact STEM Pathway Choices: urban minority youth and underrepresented STEM fields, Concordia University Chicago, United States, 120. [Link]

12. Brownstein JBR (2016) The concentration of poverty in American schools. The Atlantic, [Link]

13. Taking a closer look at the "pipeline problem". [Link]. Accessed July 2, 2021

14. Sammen HC. A social determinants of education framework, University of Colorado at Denver, United States, 2017, pp. 59. [Link]

15. Riegle-Crumb, C, King B, Irizarry Y. Does STEM stand Out? Examining racial/ethnic gaps in persistence across postsecondary fields. Educational Researcher 48(3): 133-144. [Link]

16. Robnett RD, Nelson PA, Zurbriggen EL, Crosby FJ, Chemers MM (2018) Research mentoring and scientist identity: insights from undergraduates and their mentors. Int J STEM Educ 5(41):1-14

17. Rattan A, Savani K, Chugh D, Dweck CS (2015) Leveraging mindsets to promote academic achievement: policy recommendations. Perspect Psychol Sci 20(6):721-726

18. Weatherton M, Schussler EE (2021) Success for All? A call to reexamine how student success is defined in higher education. CBE Life Sci Educ 20(1):es3

19. Thomas KM, Willis LA, Davis J (2007) Mentoring minority graduate students: issues and strategies for institutions, faculty, and students. Equal Oppor Int 26(3):178-192

20. Scott L. Why representation is so important in the STEM industry, wcnc.com. [Link]. Accessed July 2, 2021

21. Millner D. For Black college prospects, belonging and safety often top Ivy Prestige. NPR 2017 [Link]. Accessed July 2, 2021

22. Libassi CJ. The Neglected college race gap: racial disparities among college completers. Center for American Progress, 2018. [Link]. Accessed July 2, 2021

23. NSSE survey finds lack of support, unsafe feelings among minority students. 2016

24. New J, Feeling unsafe. Inside Higher Ed 2016. [Link]. Accessed July 2, 2021

25. McClain K, Perry A (2017) Where did they go: retention rates for students of color at predominantly White institutions? Coll Stud Aff Leadersh 4(1):2332-4430

26. Guzman-Lopez A. Black college students and staff make their own safety net against COVID-19 crisis. LAist 2020. [Link]. Accessed July 2, 2021

27. Miller E. For some Black students, remote learning has offered a chance to thrive, NPR. 2021. [Link]. Accessed July 2, 2021

28. Bryan C. Police don't make most black students feel safer, survey shows. 2020. [Link]. Accessed July 2, 2021 
29. Meadows-Fernandez R. Perspective I How adult mentors can help give black girls hope, and a better future, Washington Post. [Link]. Accessed July 2,2021

30. Mowatt D. Mentoring Black boys matters. Psychology Today. 2019. [Link]. Accessed July 2, 2021

31. Funk C and Parker K. Blacks in STEM jobs are especially concerned about diversity and discrimination in the workplace. Pew Research Center's Social \& Demographic Trends Project, 2018. [Link]. Accessed July 2, 2021

32. Drewis D. Why is it so hard for black women to find mentors? Girlboss. 2018. [Link]. Accessed July 2, 2021

33. Perry A. Why mentors need to stop trying to fix black and brown students. The Hechinger Report. 2015. [Link]. Accessed July 2, 2021

34. Chen S. Researchers around the world prepare to \#ShutDownSTEM and 'Strike for Black Lives', Science. 2020. [Link]. Accessed July 2, 2021

35. Ileka KM, McCluney CL, Robinson RAS. White coats, black scientists, Harvard Business Review, 2020. [Link]. Accessed July 2, 2021

36. Subbaraman N. Thousands of scientists worldwide to go on strike for Black lives, Nature. 2020. [Link]. Accessed July 2, 2021

37. Burke L. \#ShutDownSTEM, Inside Higher Ed. [Link]. Accessed July 2, 2021

38. Withdrawn: Hudlicky T. “' 'Organic synthesis-where now?' is thirty years old. A reflection on the current state of affair". Angewandte Chemie International Edition. 2020;59:12576-12576
39. McFarling UL, Troubling podcast puts JAMA, the 'voice of medicine,' under fire for its mishandling of race, STAT. 2021. [Link]. Accessed July 2,2021

40. Roberts SO, Bareket-Shavit C, Dollins FA, Goldie PD, Mortenson E (2020) Racial inequality in psychological research: trends of the past and recommendations for the future. Perspect Psychol Sci 15(6):1295-1309

41. Note from the editors: nature joins \#ShutDownSTEM, Nature. 2020. [Link]. Accessed July 2, 2021

42. \#ShutDownSTEM, MIT School of Science. 2020. [Link]. Accessed July 2, 2021

43. Dennis T. Creating antiracist spaces where Black students can breathe and thrive. Diverse Issue in Higher Education. 2020. [Link]. Accessed July 2,2021

Publisher's Note Springer Nature remains neutral with regard to jurisdictional claims in published maps and institutional affiliations. 